\title{
ENSAIO DE CARACTERIZAÇÃO DO NITOSSOLO E LATOSSOLO LONDRINENSE EM SEUS RESPECTIVOS ATRIBUTOS FÍSICOS
}

\author{
Flávio Henrique Moncef Archanjo - \\ flaviomonceff@outlook.com \\ Graduando em Engenharia Ambiental - Faculdade Pitágoras \\ Londrina \\ Guilherme Alves de Oliveira - Guilherme-alves- \\ oliveira@hotmail.com \\ Doutorando em Geociências - Universidade Estadual de \\ Londrina
}




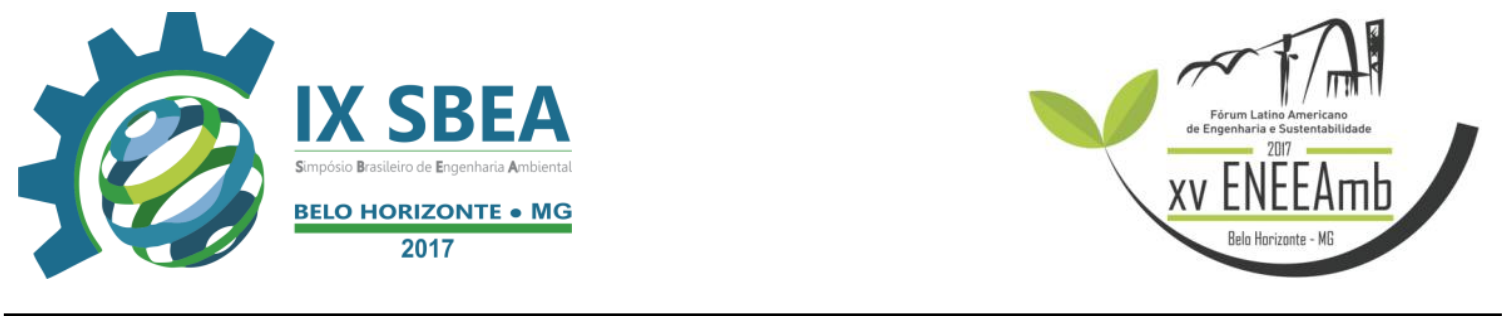

\section{RESUMO}

O presente trabalho têm o propósito em demonstrar as características de dois tipos de solos, sendo eles o Latossolo e o Nitossolo, tendo em vista a sua diferenciação, com isso foi realizado o trabalho em campo na Universidade Estadual de Londrina - UEL, onde era possível encontrar os dois tipos de solos por meio de testes tato - visual, ou seja, com a análise da coloração dos solos, testes de rigidez, testes de dilatância; em seguida foi retirado amostras dos horizontes A e B do Latossolo e o mesmo com o Nitossolo, assim essas amostras foram levadas para o laboratório para pesagem e secagem, e realização dos ensaios de Líquidez e Plasticidade, com intuito de se obter dados para a construção de um gráfico demonstrando a característica de cada um dos solos. O estudo em campo foi também parte da disciplina de geotecnia, demonstrado em aula prática a fundamentação teórica obtida em sala de aula.

Palavras - chave: Análise do solo e caracterização, Geotecnia, Pedologia.

\section{INTRODUÇÃO/OBJETIVO}

Há milhares de anos o bom solo teve sua participação significativa na agricultura, cultivando vários tipos de alimentos e também com o estudo se pode entender sua formação e estrutura e o que permitia garantir a produtividade de alimentos e entre outras culturas. O solo neste contexto é formado por um conjunto de corpos naturais tridimensionais, resultante da ação integrada do clima e organismos sobre o material de origem, condicionado pelo relevo em diferentes períodos de tempo. O perfil do solo que pode conter Regolito o solo de uma maneira geral e o solum ou saprolito onde não se considera a rocha e o horizonte $\mathrm{C}$ e dentre o perfil de um solo é dividido em horizontes, classificados em horizonte $\mathrm{O}$ (Oo e Od, sendo horizonte pouco decomposto e mais decomposto respectivamente); horizonte A (horizonte com acúmulo de matéria orgânica e argila); horizonte E (horizonte com pouca argila e minerais); horizonte B (horizonte apresenta cores vivas avermelhadas, com acumulo de argila); horizonte $\mathrm{C}$ (horizonte que apresenta material inconsolado) e o horizonte $\mathrm{R}$ (a rocha matriz), ou seja, cada horizonte possui sua característica própria, com isso, existe diferentes tipos de solo, os solos mais 


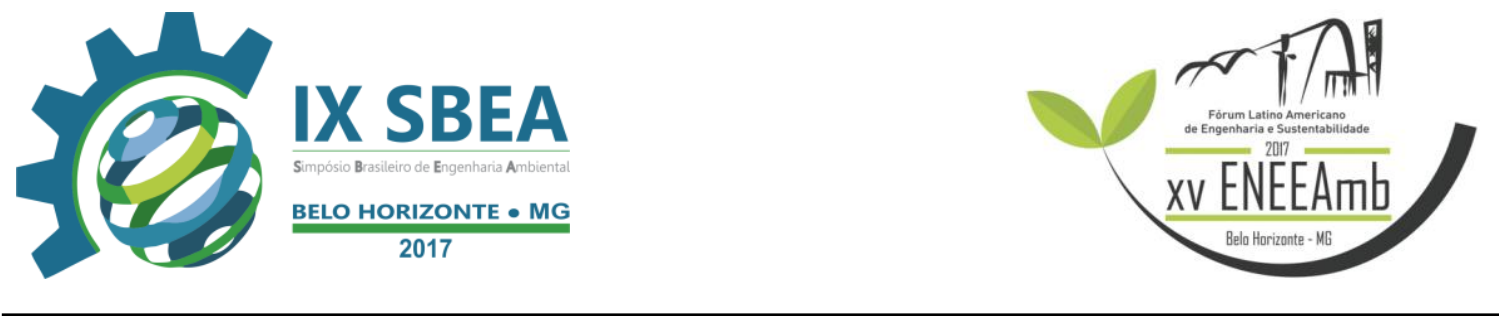

arenosos, os com maior matéria orgânica, já outros com menos matéria orgânica, tudo vai depender dos fatores de formação do solo.

Com diferentes tipos de solos, consequentemente há diferentes propriedades físico-química, capazes de determinar critérios como a fertilidade e demais atributos. $\mathrm{O}$ escopo deste trabalho é demonstrar a aplicabilidade da ciência do solo, especialmente por parte daqueles preocupados com a natureza e a identificação de atributos do solo objetivando agrupa-lós em unidades homogêneas, dentro de um sistema de classificação que sirva de referencial para a execução de levantamentos de solos e suas interpretações utilitárias.

O objetivo desse trabalho é estudar as características dos solos e sua composição mineral para determinar sua fertilidade e para definir qual solo é mais propicio a agricultura.

\section{METODOLOGIA}

"Sazonalmente, o setor agrícola tem necessidade de coletar e analisar amostras de solos agricultáveis para que seja feita correções adequadas, por exemplo, adição de calcário". (ROCHA, 2009, p. 27)

A metodologia utilizada foi estruturada em visitas de campo e ensaios laboratoriais, o estudo em campo foi realizado na Universidade Estadual de Londrina UEL, tendo como objetivo a análise das características, já os ensaios em laboratórios, se obtém os índices e limites físicos dos solos analisados.

\subsection{Teste Visual de identificação dos horizontes}

Em campo foi realizado testes de caracterização dos solos, em cada um possui uma característica diferente, assim podemos caracterizar um Nitossolo ou Latossolo pela sua coloração, estrutura e além dos testes por tato.

O primeiro solo a ser trabalhado foi o Nitossolo, de coloração avermelhado escuro, com os horizontes A e B identificados e transição planar, os horizontes possuíram uma divisão planar onde o horizonte A foi identificado através dos limites das raízes, sua estrutura é em blocos. 


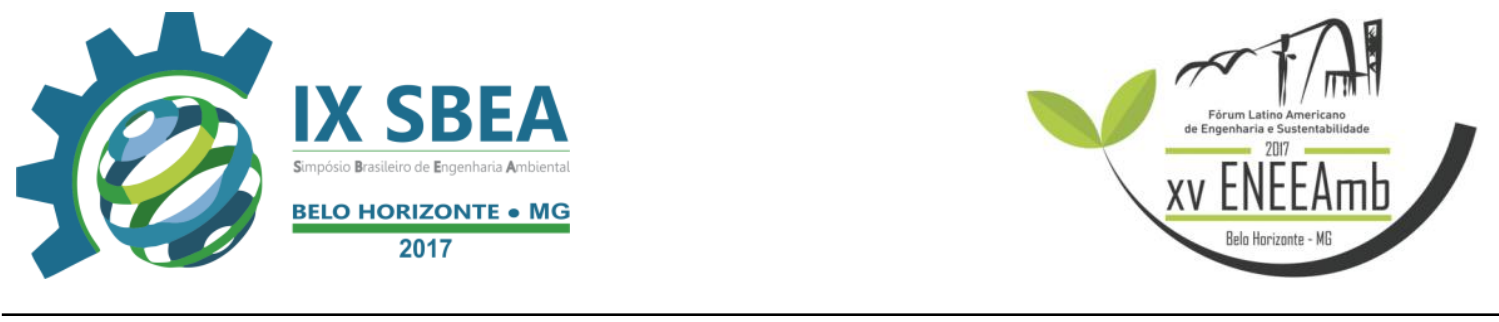

O segundo solo foi o Latossolo de coloração avermelhado mais claro por apresentar maior quantidade de oxido de ferro. Com horizontes A e B identificados e transição planar, com estrutura em blocos. Considerado um solo de maior representação em relação aos demais solos, ou seja, um solo mais comum.

Esses solos são oriundos de uma mesma rocha matriz, o que diferencia os dois tipos de solos são os fatores de formação que altera as propriedades físico - química dos mesmos, alguns desses fatores são o clima, relevo, material de origem e tempo.

\subsection{Teste tato visual}

Para CRAING (2007), a plasticidade dos solos finos pode ser avaliada por meio de testes de rigidez (ou dureza) e dilatância, descritos a seguir. Uma avaliação de resistência seca também pode ser útil.

Assim, foi retirado uma pequena amostra do primeiro solo, a ser estudado, o Nitossolo, mais especificamente do horizonte A e posteriormente do horizonte B, sendo os dois horizontes trabalhados; com as amostras em mão, foi adicionado um pouco de água e misturado na mão até obter uma maça homogenia.

Depois de ter uma massa homogênea é feito uma esfera e colocada entre os dedos polegar e indicador, com o movimento de pinça e feito uma pequena pressão com a esfera, assim pode-se estimar os padrões de retenção de água, bem como os pressupostos de pegajosidade. No horizonte "A" devido acumulo de matéria orgânica, apresenta maior retenção de água comparando com a amostra do horizonte B.

\subsection{Teste de rigidez}

Nos testes de rigidez foi retirado pequenas amostras de cada um dos horizontes em cada um dos dois tipos de solos e essas amostras foram umedecidas e feito uma pequena bola e posteriormente feito um cilindro de aproximadamente de $3 \mathrm{~mm}$.

Nessa condição, as argilas inorgânicas de alto limite de liquidez são razoavelmente rígidas e duras; as argilas de baixo limite de liquidez são mais macias e se esfarelam mais facilmente. Os siltes inorgânicos produzem um cilindro fraco e frequentemente macio que pode ser difícil de construir e se rompe e esfarela imediatamente (CRAIG, 2013, p. 9). 


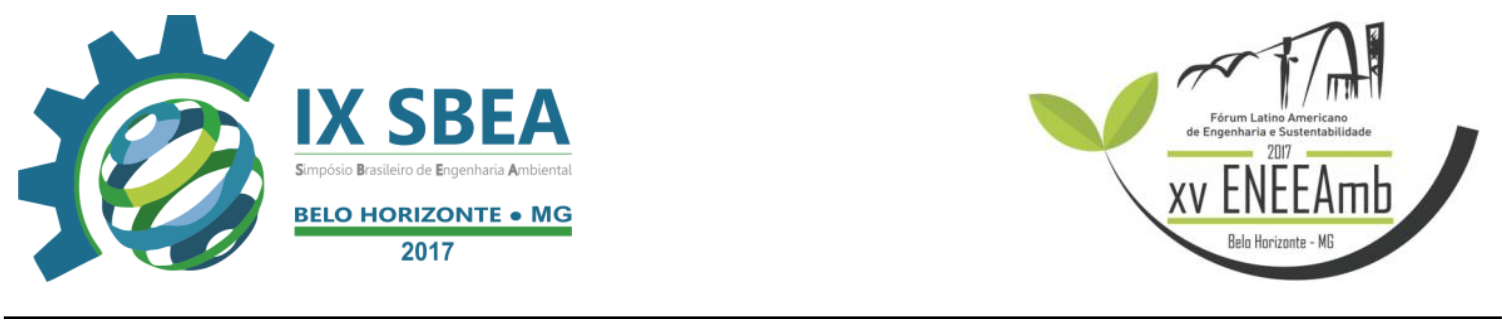

\subsection{Teste em Laboratório}

No laboratório foi realizado ensaios para determinar os Limites de Liquidez e Limite de Plasticidade, para isso as amostras foram submetidas a preparo: antes foi feito a pesagem das amostras em uma balança de precisão, em seguida as amostras foram levadas para uma estufa por uma hora a $200{ }^{\circ} \mathrm{C}$, feito a secagem das amostras e feito uma nova pesagem na balança de precisão, posteriormente foi realizado o peneiramento das amostras na mesa agitadora por 30 minutos em sequência a 5 rpm(rotações por minuto) com uma peneira de \#40(limite de 4mm), assim se obteve a separação da argila/silte da areia, tendo em vista trabalhar somente com a argila/silte. Realizado todo o preparo, as amostras já podem ser utilizadas para o ensaio de Liquidez e Plasticidade.

\subsection{Limite de Liquidez}

Segundo a NBR 6459, prescreve o método para determinação do Limite de Liquidez dos solos.

A aparelhagem necessária para o ensaio é:

- $\quad$ Estufa capaz de manter a temperatura de 60 a $65^{\circ} \mathrm{C}$ e 105 a $110^{\circ} \mathrm{C}$;

- $\quad$ Cápsula de porcelana com aproximadamente 120 mm de diâmetro;

- Espátula de lamina flexível com aproximadamente $80 \mathrm{~mm}$ de comprimento e 20 de largura;

- $\quad$ Aparelho Casagrande;

- $\quad$ Cinzel;

- $\quad$ Balança que permite pesar nominalmente $200 \mathrm{~g}$, com resolução de $0,01 \mathrm{~g}$ e sensibilidade compatível;

- Gabarito para verificar altura da queda da concha;

- $\quad$ Pêra de laboratório;

- Água.

As amostras foram colocadas nas cápsulas de porcelana e umedecidas com ajuda de uma pera de laboratório até obter uma mistura homogenia, com a mistura pronta, retira 


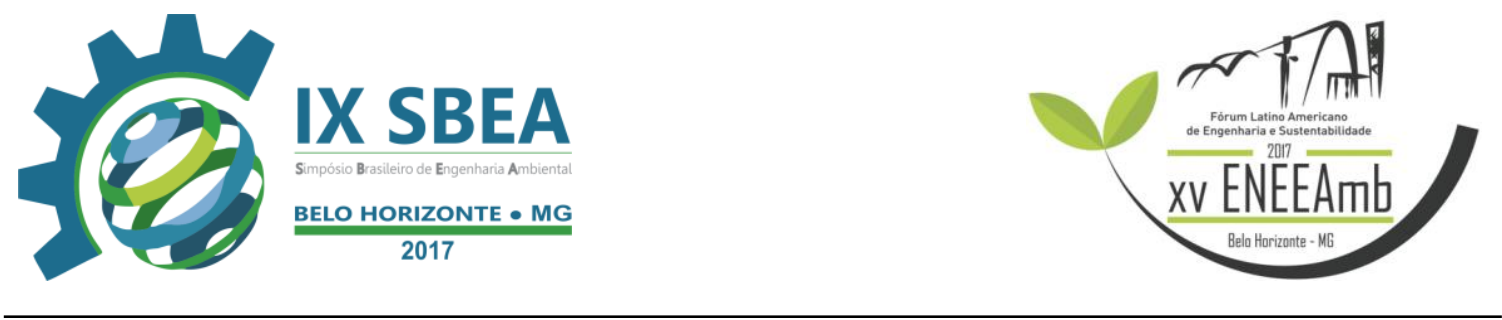

- se uma pequena amostra para colocar no aparelho Casagrande; antes de realizar os testes, primeiro é feito a calibragem do aparelho, com auxílio do gabarito afim de verificar a altura de queda da concha e ajuste realizado pelos parafusos do aparelho. Feito a calibragem é colocado a amostra na concha até cobrir dois terços da mesma, assim com o cinzel é feito um corte no meio da concha para delimitar o limite de liquidez, assim se pode realizar os ensaios dando golpes até que as duas metades se unirem.

A determinação do limite de liquidez (LL) é feita pelo aparelho Casagrande, que consiste em um prato de latão, em forma de concha, sobre um suporte de ebonite; por meio de um excêntrico imprime - se ao prato, repetidamente, quedas de altura de $1 \mathrm{~cm}$ e intensidade constante. (CAPUTO, 2012, p. 54)

\subsection{Limite de Plásticidade}

Pela NBR 7180 determina o método para determinação do limite de plasticidade e para o cálculo de do índice de plasticidade dos solos.

A aparelhagem necessária para o ensaio é:

- $\quad$ Estufa capaz de manter a temperatura de 60 a $65^{\circ} \mathrm{C}$ e 105 a $110{ }^{\circ} \mathrm{C}$;

- $\quad$ Cápsula de porcelana com aproximadamente $120 \mathrm{~mm}$ de diâmetro;

- Espátula de lamina flexível com aproximadamente $80 \mathrm{~mm}$ de comprimento e 20 de largura;

- $\quad$ Balança que permite pesar nominalmente $200 \mathrm{~g}$, com resolução de $0,01 \mathrm{~g}$ e sensibilidade compatível;

- Gabarito cilíndrico para comparação, com $3 \mathrm{~mm}$ de diâmetro e cerca de $100 \mathrm{~mm}$ de comprimento;

- $\quad$ Placa de vidro de superfície esmerilhada, com cerca de $30 \mathrm{~cm}$ de lado;

- $\quad$ Pêra de laboratório;

- Água.

Feito o mesmo procedimento anterior, até obter uma mistura homogênea, com o material de ensaio pronto, foi retirado uma pequena fração da amostra e foi modelando pequenas esferas, estas foram roladas na placa de vidro com pressão na palma da mão até que a pequena esfera forma um cilindro, quando a amostra fragmentasse durante o 
procedimento ela foi levado para a cápsula e adicionado água para homogeneizar e logo foi repetido o procedimento, assim com a aguda do gabarito foi verificado o seu diâmetro de $3 \mathrm{~mm}$, com isso ao atingir os $3 \mathrm{~mm}$ a amostra foi amassado e repetido o procedimento por três vezes.

“O Índice de Plasticidade define a zona em que o terreno se acha no estado plástico e, por ser máximo para as argilas e mínimo, ou melhor, nulo para as areias, fornece um critério para se organizar do caráter argiloso de um solo". (CAPUTO, 2012, p. 56)

CRAIG (2007) diz que o limite inferior do intervalo de valores de teor de umidade no qual o solo exibe comportamento plástico são definidos como Limite de Liquidez ( $\mathrm{W}_{\mathrm{L}}$ ) e Limite de Plasticidade (WP), respectivamente. Assim o intervalo de valores dos teores de umidade é definido como índice de Plasticidade (IP).

$$
I P=w L-w P
$$

O teor de umidade natural (w) em um solo (ajustado a um teor de umidade equivalente da fração que passa na peneira de $425 \mu \mathrm{m}$ ) relativo aos limites de liquidez e plasticidade pode ser representado por um intermédio do Índice de Liquidez $\left(\mathrm{I}_{\mathrm{L}}\right)(\mathrm{CRAIG}$, 2007, p. 6).

$$
I L=w-\frac{w p}{I P}
$$

O grau de Plasticidade da fração do tamanho de argila de um solo é expresso pela relação entre o índice de Plasticidade e a porcentagem de partículas com o tamanho de argila no solo; essa relação é chamada de atividade (CRAIG, 2007, p. 0).

Craig (2007) informa que os Limites de Liquidez e Plasticidade são determinados por meio de procedimentos arbitrários de ensaios, detalhados completamente na BS 1377 (Parte 2) [2]. A amostra de solo é seca suficiente de modo a permitir que seja esfarelada e partida.

"Entende - se por teor de umidade do um solo como sendo a razão entre o peso da água contida num certo volume de solo e o peso da parte sólida existente neste mesmo volume, expressa em porcentagem". (CAPUTO, 2012, p.39) 


$$
h \%=\frac{P a}{P S} * 100
$$

\section{RESULTADOS E DISCUSSÕES}

Realizado todos os testes, temos os resultados e o gráfico que demonstra o comportamento do solo.

Tabela 3.0 - Resultado de análises do Nitossolo

\begin{tabular}{|c|c|c|}
\hline Amostras & Teor de umidade (\%) & $\mathrm{N}^{\mathrm{o}}$ de golpes \\
\hline Amostra 0 & 18,47 & 50 \\
\hline Amostra 1 & 7,97 & 50 \\
\hline Amostra 2 & 13,68 & 50 \\
\hline Amostra 3 & 17,92 & 50 \\
\hline
\end{tabular}

Fonte: Laboratório Pitágoras

Tabela 3.1 - Resultado de análise do Latossolo

\begin{tabular}{|c|c|c|}
\hline Amostras & Teor de umidade (\%) & $\mathrm{N}^{\circ}$ de golpes \\
\hline Amostra 0 & 29,22 & 11 \\
\hline Amostra 1 & 1,48 & 11 \\
\hline Amostra 2 & 31,02 & 11 \\
\hline Amostra 3 & 51,79 & 11 \\
\hline
\end{tabular}

Fonte: Laboratório Pitágoras

Figura 2.0 - Gráficos Teor de umidade e No de golpes - Nitossolo/Latossolo
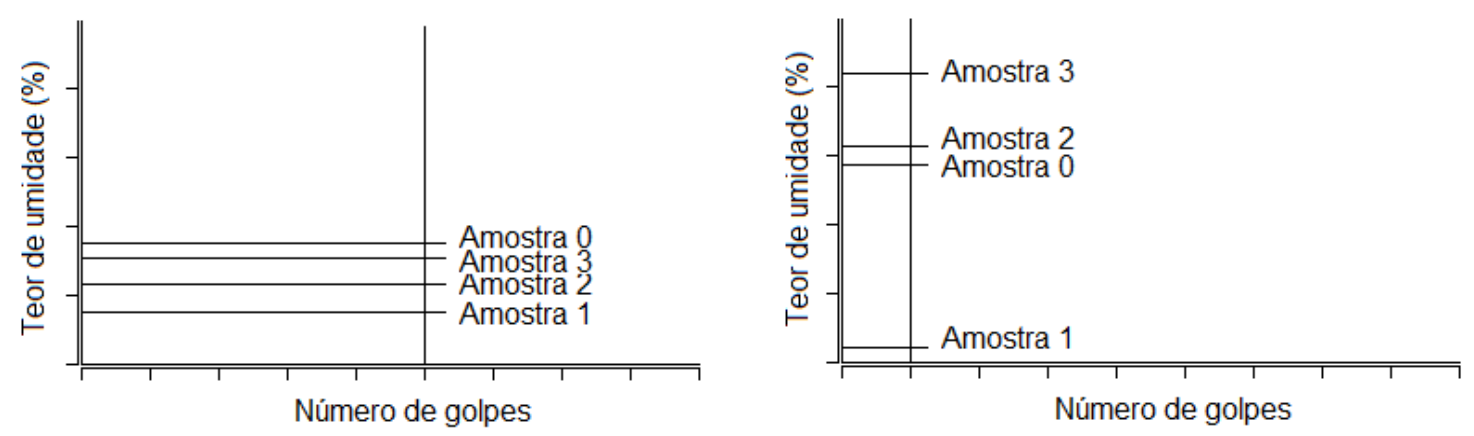
Fonte: Laboratório Pitágoras

Com os resultados obtidos, foi identificado distinções claras entre os solos, sendo o Latossolo menos fértil por não apresentar uma variedade mineral diferente, pois por causa do intemperismo intenso e duradouro, a maioria dos Latossolos é muito pobre em nutrientes vegetais.

LEPSCH (2010, p. 98) diz que muitos dos Latossolos eram, até há algumas décadas, considerados solos problemáticos para a agricultura, pela baixa fertilidade natural. Por outro lado, a pequena coerência entre os agregados, aliada a grande espessura, faz com que os Latossolos sejam preferidos para muitos trabalhos de engenharia, que envolvem escavações e aterros.

O Nitossolo possui uma gama de Minerais, além do Latossolo ter um limite de liquidez alto em relação ao Nitossolo, porém com plasticidade baixa pelo acúmulo de argila o que faz fragmentar rapidamente no teste de plasticidade. "Os Nitossolo são medianamente profundos, bastante intemperados e com fraca diferenciação de horizontes, mas com macro agregados nítidos e reluzentes do horizonte B”. (LEPSCH, 2010, p. 100)

"Os solos da Região Sul do Brasil, foram muito procuradas para o plantio de café, mas agora são mais utilizadas para cultivos anuais (soja, milho, trigo etc.), principalmente pela ocorrência periódica de geadas, que são muito prejudiciais aos cafezais". (LEPSCH, 2010, p. 142)

De acordo com ROCHA (2009, p. 168) o solo pode ser representado como um ciclo natural em que participam fragmentos de rochas, minerais, água, ar, seres vivos e seus detritos em decomposição, fazendo parte de um ecossistema, sendo um solo rico em nutrientes e extremamente fértil.

\section{CONSIDERAÇÕES FINAIS}

O tipo de solo encontrado em uma região é muito importante para definir vários outros fatores, como se a região será propícia para a agricultura, qual será o tipo de cultua, entre outros aspectos naturais. A qualidade e características de solo vão depender de diversos fatores, como o tipo de rocha do qual o solo se originou, o clima do local, a _matéria orgânica presente e até a vegetação encontrada no local. 
O tipo da solo influência até mesmo o desenvolvimento econômico de uma região, pois a agricultura depende da riqueza de nutrientes que gera uma grande produção, aumentando a renda dos produtores e entre outros aspectos de desenvolvimento de uma comunidade.

Com isso, através dos estudos realizados, foi verificado composição de minerais em abundancia nos Nitossolos com grau de fertilidade alta, bom para o cultivo de leguminosas e milho, entretanto a necessidade de ser irrigado com mais frequência em relação ao Latossolo, tendo em vista o Nitossolo possuir um teor de umidade baixo. Já o Latossolo tem um grau baixo de nutrientes minerais que consequentemente necessita da utilização de fertilizantes para garantir uma produção de qualidade e servindo para o cultivo do café.

\section{REFERENCIAS BIBLIOGRAFICAS}

. NBR 6457: Preparação das amostras

NBR 6457: Preparação das amostras.

NBR 6459: Método de ensaio.

ASSOCIAÇÃO BRASILEIRA DE NORMAS TECNICAS - ABNT. NBR 6459: Solo - Determinação do Limite de Liquidez. Rio de Janeiro, 1984.

ASSOCIAÇÃO BRASILEIRA DE NORMAS TECNICAS - ABNT. NBR 7180: Solo Determinação do Limite de Plasticidade. Rio de Janeiro, 1984.

CRAIG. R. F: Mecânica dos solos, Rio de Janeiro, $7^{\text {a }}$ ed. p. 2-15, 2013.

GUERRA. A. J. T.: Geomorfologia e Meio Ambiente, Rio de Janeiro, 11 a ed, p.13-60, 2012.

LEPSCH, I. F. Formação e Conservação dos Solos. 2a . ed. São Paulo: Oficina de testos, 2010.

CAPUTO, H. P. Mecânica dos Solos e suas Aplicações. 6a . ed. Rio de Janeiro: LTC, v. I, 2012.

ROCHA, J. C. Introdução a Química Ambiental. 2a . ed. Porto Alegre: Bookman, 2009. 